\title{
Analysis on the Construction of Digital Resources in University Libraries in the Environment of "Internet+"
}

\author{
Lina Wang \\ Harbin University of Commerce, Harbin, Heilongjiang Province, China 150028 \\ E-Mail: wanglina_6688@126.com
}

Keywords: university library; digital resource; construction; "Internet+"

\begin{abstract}
This paper reviews the current situation and research background of digital resources construction of university libraries in the "Internet+" environment, analyzes the problems faced at present, and further explores how to better promote the construction of digital resources in college libraries, with a view to future practice. And the research work has some inspiration.
\end{abstract}

\section{Introduction}

With the "Internet+" action plan proposed ${ }^{[1]}$, various industries have been impacted and influenced by the Internet and information technology, and the traditional university library have also ushered in new opportunities and challenges. With the development of network and digitalization, university libraries have become an indispensable part of the construction and development in university libraries ${ }^{[2]}$. At present, university libraries still have some problems in the process of the construction of digital resources. Therefore, analyzing the existing problems and finding new ideas for the construction of digital resources in university libraries has become the most urgent problem that university libraries need to solve.

\section{Survey of Digital Resources Construction in University Libraries}

\subsection{Research status.}

From the definition of digital resources at home and abroad, foreign research on the construction of digital resources in university libraries started earlier. As early as 1997, the IFLA (International Federation of Library Associations, IFLA) made a clear definition and classification of digital resources $^{[3]}$. In 2017, in the letter of recommendation issued by the Ministry of Education's Library and Information Work Steering Committee of the Ministry of Education to the Ministry of Education, the quantity and category of digital resources were clearly defined, and four categories of digital resources were proposed ${ }^{[4]}$. Namely: e-books, e-journals, dissertations, audio and video.

This paper carries out fuzzy retrieval in CNKI (China National Knowledge Infrastructure, CNKI) with the theme of "university library" and "digital resource construction" (the retrieval date is August 14th, 2018), excluding irrelevant documents and duplicate documents such as news reports and documentary. A total of 896 articles were obtained, of which 771 (86.05\%) were mainly journal articles, 101 (11.27\%) were master's thesis, 13 (1.45\%) were doctoral thesis, and $1(1.23 \%)$ were domestic conferences. Gao Jingwen ${ }^{[5]}$ proposed the contents, specific practices, and experience in the construction and utilization of digital resources, which was the first article about the construction of digital resources in university libraries in China. Since then, domestic scholars' research on the construction of digital resources in university libraries has been increasing year by year, reaching a peak in 2012, and the number of subsequent publications has decreased slightly compared with 2012, but the level and depth of the literature have gradually increased, and theoretical research has also gone from shallow to deep. In recent years, the research results have mainly focused on the standardization of digital resources construction, quality evaluation, foreign experience, and open resources sharing. 


\subsection{Purchase fee and collection amount.}

With the continuous development of the "Internet+" environment, the acceleration of networking and digitization, the construction of digital resources has become increasingly important in the survival and development of university libraries. The purchase of digital resources in university libraries has increased year by year. In 2016, the average purchase fees of digital resources in China's university libraries was about 2.881 million Yuan, accounting for $54.4 \%$ of the purchase fees of literature information resources. The proportion increased by 3.1 percentage points compared with 2015, and the average value increased year by year ${ }^{[6]}$.

The Chinese digital resources of universities almost cover all the major Chinese databases in China. CNKI Journal Full Text, Superstar Huiya e-book, VIP Journal Resource Integration Service Platform, CNKI dissertation and Duxiu Knowledge Search Database, these five Chinese databases have the highest repurchase rate ${ }^{[7]}$. Foreign language digital resources are also extremely rich, involving almost all subject areas; the highest repurchase rate of university reconstruction are comprehensive foreign language full-text databases, such as EBSCO ASP/ASC and BSP/BSC, Springer E-Journal ${ }^{[6]}$.

\section{Problems in the Construction of Digital Resources in University Libraries}

The construction of digital resources is the inevitable outcome of "Internet+ university library" is of vital importance to the survival and development of libraries. However, there are still some problems to be solved in the construction of digital resources in university libraries.

\subsection{Restricted by database suppliers.}

"Peking University stopped using CNKI in 2016" caused widespread attention and heated discussion in society. In recent years, the sharp increase in the price of CNKI has become unbearable to many universities. Not only did Peking University suspend the renewal of the order due to the price hike, but many universities in China have also encountered such problems and stopped using CNKI ${ }^{[8]}$. CALIS (China Academic Library and Information System, CALIS) had a breakdown in the negotiations due to the price hike of the Elsevier database, which led to the interruption of the partnership ${ }^{[9]}$. Faced with the endless price hikes of journals, the library has never stopped fighting with publishers and has been seeking solutions. All of these events reflect the contradiction between the increasing database price and the limited purchase fees of digital resources in university libraries.

\subsection{Unbalanced development of digital resources in inter-library universities.}

In 2016, the minimum investment in the digital resource purchases fees was only 7641Yuan, and the maximum value was 41.691 million Yuan. The difference between them is 5456.3 times $^{[4]}$. According to relevant survey statistics ${ }^{[10]}$, more than $90 \%$ of the 985 engineering university libraries have more than 100 databases, and at least 20\% have more than 200 databases, which is beyond the reach of ordinary university libraries.

\subsection{Repeat order for the same resource.}

In university libraries, the original paper periodicals and electronic periodicals are often reordered. CNKI, VIP Journal Resource Integration Service Platform and Wan Fang Data Resource System all provide academic journals, some of them are identical. On the other hand, the same databases will also be introduced between different universities. Such repeated orders will undoubtedly bring helpless and unnecessary waste of fees to the library.

\subsection{Lack of unified standards.}

In the process of data resource construction in China, the national or trade association has not yet formulated standards and norms for digital resources construction ${ }^{[11]}$. According to their own needs, each database service provider is in charge of its own needs, and it is free to develop. In the process of use, users find various systems, difficult operation, poor data compatibility and interoperability, 
and different raw data processing.

\subsection{Insufficient resource integration.}

The optimal integration of digital resources, that is, the classification of digital resources according to specific requirements ${ }^{[12]}$. At present, university libraries generally have abundant digital collection resources. However, due to the different attributes of each resource system, the retrieval requires different usage and authentication formats, so users cannot obtain all information at one time. In addition, the emergence and widespread development of a new reading mode, digital reading, has also put forward new requirements for the optimal allocation of resources in universities, and the existing allocation has been unable to meet the new requirements.

\subsection{Hidden dangers in resource storage and security.}

The increasing geometrical data every day brings advantages to the library, but also brings hidden dangers to the storage and security. The storage of massive digital resources in University Libraries shows the characteristics of complicated varieties, disorderly structure and large storage space. With the help of cloud accounting, a lot of data is stored in various "clouds", and the dynamic nature of users and the disorder of cloud accounting make the data stored have security risks, especially the personal information of users and important data of libraries.

\subsection{Lack of direction in self-built characteristic databases.}

Some university libraries have self-built characteristic databases, most of which include the multimedia resources are relatively insufficient, the digital reading resources suitable for mobile terminals are insufficient, and the further organization, exploration and aggregation of digital resources are lacking. In addition, the number of e-books and e-journals in self-built databases is relatively abundant, while the development of public network information resources is relatively less.

\subsection{Lack of professional talents.}

According to the survey ${ }^{[13]}$, in 2016 , the number of non-graphic professional subjects in China's university libraries was mostly, while the number of librarians with a background in library science or information science accounted for less than one-third of the total. In addition, the level of professional and technical personnel also has a phenomenon of unevenness. These problems have limited the service level of the library to a certain degree.

\section{Optimization Measures for the Construction of Digital Resources in University Libraries}

For university libraries with limited purchase fees, the following measures can be used to completely change the existing problems in the construction of digital resources.

\subsection{Actively explore the mechanism of co-construction and sharing, and increase the integration of digital resources.}

The co-construction and sharing of digital resources is an important strategy for university libraries to realize the standardization of digital resources, avoid repeated ordering, and curb the imbalance of digital resources in inter-library collections.

Many countries and regions are engaged in digital resource procurement through the establishment of library alliance, which first appeared in the 1960s and 1970s. Typical domestic alliances include CALIS and newly established DRAA, which have organized regional digital resource procurement, showing the strength of Chinese university library team, increasing the promotion and use of foreign and Chinese digital resources, narrowing the gap between small libraries and large libraries, and improving the quality of the introduction of university databases ${ }^{[14]}$. Universities library should work together to join or form library alliance, actively exploring the way management system and the allocation of resources, formulate unified standards and planning. To realize the "one-stop" service of high-level and convenient information resources, such as 
inter-library document transmission, inter-library loan and joint borrowing.

University libraries need strengthen the research and practice of digital resources integration, optimize and integrate all kinds of resources, including open access resources and shared resources, so as to maximize the utilization of digital resources. According to the actual situation, a complete resource integration and disclosure system should be established to achieve effective integration and disclosure of the entire resource at multiple levels and in all directions.

\subsection{Provide security for the construction of digital resources.}

University libraries need to build advanced modern technology equipment, high-performance computer network, and perfect service system and query system to ensure users to retrieve information, transmit and obtain digital information resources. An intelligent library should first comprehensively transform the existing campus LAN, upgrade the internal platform of the campus network, upgrade and expand the server capacity, constantly improve the hardware facilities of the library, and ensure the efficient operation of the library.

\subsection{Broaden the direction of the construction of characteristic databases.}

The construction of characteristic database is an important content of library digitization. At present, the university library should digitize its collection resources and cultural resources with its own features. In the construction, we should adhere to the principles of standardization, timeliness and completeness, pay attention to the sharing of copyright and information, set up relevant database websites and codes according to actual needs, describe different types of data resources in detail, provide one-stop service for users from the source, so as to meet users' needs to the greatest extent.

\subsection{Introduce professional talents and strengthen team building.}

Indian library scholar S.R. Ranganathan put forward that "library is a growing organism", and emphasized the role of librarians in the development of library ${ }^{[15]}$. The construction of digital resources in university library should not only upgrade the hardware, but also upgrade the software. It is necessary to have a talent team with reasonable structure. It is particularly important to correctly understand and grasp the type of demand for the construction of digital resources in university libraries.

\section{Conclusion}

In the "Internet+" environment, traditional university libraries have been and will continue to face more and more opportunities and challenges. Only by actively responding to challenges and making bold innovations can we win better development. The construction of digital resources in university library has removed the walls between schools, broken the distance between libraries and libraries, and eliminated the resource gap between libraries of different scales. It not only expands the literature information resources of university library, but also promotes the reform of service mode and function, and makes university library become the cradle of knowledge innovation.

\section{Acknowledgements}

This work was financially supported by the Heilongjiang Provincial Higher Education Library and Information Working Committee Project (2015-B-064), Harbin University of Commerce Young Innovative Talent Support Project (2016QN040) and Doctoral Research Program Launched by Harbin University of Commerce (15RW32).

\section{References}

[1] Li Keqiang. 2015 government work report (full text record) (In Chinese) [EB/OL]. http://lainghui.people.com.cn/2015npc/n/2015/0305/c394298-26642056-7,html,2015-07-03. 
[2] He Xiurong, ed. Research on university libraries in transitional development (In Chinese) [M]. Beijing: China Agricultural University Press, 2013.2-3.

[3] IFLA.ISBD (ER): International Standard Bibliographic Description for Electronic Resources [OL]. [2010-10-28]. http://archive.ifla.org/VII/s13/pubs/isbd.htm

[4] Information on http://www.yidianzixun.com/article/0IA6T6MM

[5] Gao Jingwen. The Construction and Utilization of Digital Resources in Network Environment (In Chinese) [J]. Journal of Information, 2001(06):70-71.

[6] Wang Bo, Wu Hanhua and Song Jifang etal, Zhu Qiang.A Survey of the Development of University Libraries in 2016 (In Chinese) [J].Library Work in Colleges and Universities, 2017, 37(06): 20-34.

[7] Working Group on Literature Resources Annual Report of the Library and Information Work Steering Committee of the Ministry of Education of the Ministry of Education. Report on the Development of Literature Resources of University Libraries (2010-2014) [Z].2015-10.

[8] Information on http://www.edu.cn/edu/gao_deng/gao_jiao_news/201604/t20160407_1384140.shtml

[9] Zhao Xixia, Li Qingfen. Exploring the Construction of Foreign Language Database Resources of University Libraries under the Condition of Monopoly Market (In Chinese) [J].Journal of Shandong Library Science, 2012(01):87-90.

[10] Mao Yihong, Zhu Qiang, Wang Bo. The Status Quo and Prospect of Digital Reading Service in University Libraries (In Chinese) [J]. Journal of Academic Libraries, 2017, 35(01):85-91.

[11] Xi Yajun. Research on the Status Quo and Development Trend of Digital Resources Construction in University Libraries (In Chinese) [J].Journal of Henan Library Science, 2016, 36(02):41-43.

[12] Ma Wenfeng. Research on Digital Resources Integration (In Chinese) [J]. Journal of Library Science in China, 2002, 28(4): 64-67.

[13] Sun Yuanyuan, LI Feng, QIU Xiaowei. Investigation and Analysis of the Construction of Librarians in University Libraries in China (In Chinese) [J]. Journal of Jiangxi Normal University (Philosophy and Social Sciences Edition), 2016, 49(05):121-125.

[14] Li Fang, Peng Jia, Yang Mei, etc. The construction of subject information resources (In Chinese) [M]. Shanghai: Shanghai Jiaotong University Press, 2010.120-121.

[15] S.R. Ranganathan, ed. The Five Laws of Library Science (In Chinese) [M]. Beijing: Bibliographic Literature Publishing House, 1988. 